\title{
Epidemiology, Risk Factors, and Clinical Features of Intracerebral Hemorrhage: An Update
}

\author{
Sang Joon An, Tae Jung Kim, Byung-Woo Yoon \\ Department of Neurology, Seoul National University Hospital, Seoul, Korea
}

Intracerebral hemorrhage (ICH) is the second most common subtype of stroke and a critical disease usually leading to severe disability or death. ICH is more common in Asians, advanced age, male sex, and low- and middle-income countries. The case fatality rate of ICH is high $140 \%$ at 1 month and $54 \%$ at 1 year), and only $12 \%$ to $39 \%$ of survivors can achieve long-term functional independence. Risk factors of ICH are hypertension, current smoking, excessive alcohol consumption, hypocholesterolemia, and drugs. Old age, male sex, Asian ethnicity, chronic kidney disease, cerebral amyloid angiopathy (CAA), and cerebral microbleeds (CMBs) increase the risk of ICH. Clinical presentation varies according to the size and location of hematoma, and intraventricular extension of hemorrhage. Patients with CAA-related ICH frequently have concomitant cognitive impairment. Anticoagulation related $\mathrm{ICH}$ is increasing recently as the elderly population who have atrial fibrillation is increasing. As non-vitamin K antagonist oral anticoagulants (NOACs) are currently replacing warfarin, management of NOAC-associated ICH has become an emerging issue.

Keywords Cerebral hemorrhage, Epidemiology, Incidence, Risk factors, Neurologic manifestations
Correspondence: Byung-Woo Yoon Department of Neurology, Seoul National University Hospital, 101 Daehak-ro, Jongno-gu, Seoul 03080, Korea Tel: $+82-2-2072-2875$

Fax: +82-2-3673-1990 E-mail: bwyoon@snu.ac.kr

Received: July 16, 2016 Revised: December 18, 2016 Accepted: January 6, 2017

\begin{abstract}
This work was supported by the Korea Health Technology R\&D project (HI10 C2020) and by the Ministry of Health and Welfare, Republic of Korea (HI16C1078).

The authors have no financial conflicts of interest.
\end{abstract}

\section{Introduction}

Intracerebral hemorrhage (ICH) is usually caused by rupture of small penetrating arteries secondary to hypertensive changes or other vascular abnormalities. ${ }^{1-3}$ In developed countries, the incidence of hypertensive ICH has decreased with the improvement of blood pressure control. ${ }^{4}$ However, in developing countries, the burden of $\mathrm{ICH}$ has not decreased. ${ }^{5}$ The outcome of $\mathrm{ICH}$ is variable, depending on hematoma volume, location, extension to ventricles, and other factors. ${ }^{6}$ However, compared to ischemic stroke, ICH leads to higher mortality and more severe disability. In this review, we will summarize the epidemiology, pathophysiology, risk factors, prognostic factors, and clinical manifestation of $\mathrm{ICH}$.

\section{Epidemiology}

\section{Incidence}

ICH accounts for approximately $10-20 \%$ of all strokes ${ }^{8,9}$
8-15\% in western countries like USA, UK and Australia, 10,11 and $18-24 \%$ in Japan ${ }^{12}$ and Korea. ${ }^{4}$ The incidence of ICH is substantially variable across countries and ethnicities. The incidence rates of primary $\mathrm{ICH}$ in low- and middle-income countries were twice the rates in high-income countries (22 vs. 10 per 100,000 person-years) in 2000-2008. ${ }^{8}$ In a systematic review of 36 population-based epidemiological studies, the incidence rate of $\mathrm{ICH}$ per 100,000 person-years was 51.8 in Asians, 24.2 in Whites, 22.9 in Blacks, and 19.6 in Hispanics. ${ }^{13}$ In a population-based US study identifying 1,038 patients who were hospitalized for ICH, American black people had a higher incidence of ICH compared to white people; per 100,000 person-years, 48.9 vs. $26.6 .^{14}$

The incidence of $\mathrm{ICH}$ increases with advanced age. ${ }^{15} \mathrm{~A}$ recent inpatient database study from the Netherlands based on retrospective cohort study reported that the incidence of ICH per 100,000 was 5.9 in $35-54$ years, 37.2 in 55-74 years, and 176.3 in 75-94 years old in 2010. For all ages, the annual incidence rate per 100,000 persons was higher in men than in women; 5.9 
vs. 5.1 in people aged $35-54$ years, 37.2 vs. 26.4 in those aged 55-74 years, and 176.3 vs. 140.1 in those aged $75-94$ years. ${ }^{16}$ In a German study analyzing database of a regional prospective stroke registry between 2007 and 2009, 34\% of 3,448 patients with ICH were aged 80 years or more. ${ }^{17}$

The Global Burden of Disease 2010 Study showed a 47\% increase in the absolute number of hemorrhagic stroke (including ICH and subarachnoid hemorrhage) worldwide between 1990 and 2010. The largest proportion of ICH incident cases (80\%) and deaths (63\%) occurred in low- and middle-income countries such as Sub-Saharan Africa, Central Asia and Southeast Asia. During the two decades, the age-adjusted incidence rate of hemorrhagic stroke reduced by $8 \%$ (95\% confidence interval [CI]: 1-15) in high-income countries, whereas it increased by 22\% (95\% Cl: 5-30) in the low- and middle-income countries. ${ }^{5}$ A population-based study in the United Kingdom showed that the incidence of ICH associated with hypertension in patients less than 75 years of age has declined since the early 1980s with the improved control of hypertension. However, for all ages, the number of ICH cases remained stationary, which was likely to be attributed to an increase of non-hypertensive lobar ICH presumably caused by amyloid angiopathy in elderly people aged over 75 years and a recent increase in $\mathrm{ICH}$ associated with antithrombotic therapy. As the population ages, the incidence of ICH due to amyloid angiopathy may further rise in the future. ${ }^{18}$ The incidence of ICH in Japan has declined significantly due probably to the better control of hypertension. ${ }^{12}$ In Korea, there has been no population-based study on the trend of the ICH incidence. Estimation based on nationwide health insurance database indicates that the incidence of hemorrhagic stroke in Korean people aged between $35-74$ years decreased annually by $1.82 \%{ }^{4}$ On the other hand, a systematic review of 56 population-based studies showed that the overall age-adjusted incidence rate of primary $\mathrm{ICH}$ by pooling data from high-income countries showed no significant change between 1980 and $2008 .{ }^{8}$

\section{Fatality}

A case fatality rate of $\mathrm{ICH}$ is approximately $40 \%$ at 1 month and $54 \%$ at 1 year. Only $12 \%$ to $39 \%$ of patients achieve longterm functional independence. A meta-analysis of $\mathrm{ICH}$ outcomes between 1980 and 2008 showed no appreciable change in case fatality rate over that time period, ${ }^{13}$ but retrospective studies of large cohorts in the United Kingdom and United States showed a significant decrease in case fatality since $2000 .{ }^{19,20} \mathrm{~A}$ worldwide stroke epidemiology study revealed that early stroke case fatality (21-day to 1-month) varied substantially among countries and study periods; the case fatality rate was $25-30 \%$ in high-income countries while it was 30-48\% in low- to middle-income coun- tries. ${ }^{8}$ Decrease in the ICH fatality rate might be attributed to the improvement of critical care. ${ }^{21}$ In Korea, the case-fatality rate of ICH estimated from the nationwide insurance database was high as $35 \%$ in 2004 . However, the in-hospital 30-day case-fatality rate in 2009 was much lower as $10.2 \%{ }^{4}$

\section{Pathophysiology}

\section{Hypertensive vascular change}

$\mathrm{ICH}$ is usually caused by ruptured vessels that are degenerated due to long-standing hypertension. Responsible arteries show prominent degeneration of the media and smooth muscles. ${ }^{2} \mathrm{Fi}-$ brinoid necrosis of the sub-endothelium with micro-aneurysms and focal dilatations may be seen in some patients. Lipohyalinoses, prominently related to long-standing hypertension, is most often found in non-lobar $\mathrm{ICH}^{22}$ whereas cerebral amyloid angiopathy (CAA) is relatively more common in lobar $\mathrm{ICH}^{23}$

\section{Cerebral amyloid angiopathy}

CAA is characterized by the deposition of amyloid- $\beta$ peptide at capillaries, arterioles, and small- and medium-sized arteries in the cerebral cortex, leptomeninges, and cerebellum. ${ }^{24} \mathrm{CAA}$ in the cerebral small vessel leads to sporadic ICH in elderly people, commonly associated with variations in the gene encoding apolipoprotein E epsilon 2 and 4 in chromosome 19..$^{25,26}$ Duplication of the APP locus on chromosome 21 is also found in families with familial early-onset Alzheimer disease and CAA. CAA-related ICHs occur mainly in the elderly subjects while a rare familial syndrome may manifest in relatively young patients. ${ }^{25}$

\section{Molecular pathophysiology}

The initial injury mechanism in ICH is compressing brain parenchyma by hematoma's mass effect, resulting in physical disruption of parenchymal architecture. ${ }^{27}$ Increased intracranial pressure due to expansion of hematoma can affect blood flow, mechanical deformation, neurotransmitter release, mitochondrial dysfunction and membrane depolarization. As a result, neuronal injury in perihematomal area contains the edema and inflammatory environment by blood-derived factors. ${ }^{28-30} \mathrm{~A}$ secondary mechanism of brain injury is related to clotting cascade, in particular thrombin, after endothelial damage and hemoglobin breakdown. ${ }^{31-33}$ Thrombin causes inflammatory cells to infiltrate the brain, proliferation of mesenchymal cells, formation of brain edema and scar tissue. ${ }^{34}$ Thrombin binds to protease-activated receptors 1 and activates the central nervous system microglia and complement cascade. As a result, multiple immune pathways are activated, which contributes to apoptosis and necrosis. Heme influx in neuron after endothelial damage leads to iron re- 
lease and neuronal insult. ${ }^{1,2,7}$

\section{Risk factors}

Modifiable risk factors include hypertension, cigarette smoking, excessive alcohol consumption, decreased low-density lipoprotein cholesterol, low triglycerides and drugs including anticoagulant, antithrombotic agent, and sympathomimetics. Nonmodifiable risk factors include old age, male sex, CAA, and Asian ethnicity (Table 1). ${ }^{35,36}$ The INTERSTROKE study, an international case-control study of 6,000 individuals in 22 countries worldwide, showed that hypertension, smoking, waist-to-hip ratio, diet, and high alcohol intake were major risk factors for $\mathrm{ICH}_{\text {, and }}$ these modifiable risk factors accounted for $88.1 \%$ of the population-attributable risk. ${ }^{37}$

Hypertension is the most important risk factor for spontaneous $\mathrm{ICH}$, and the contribution of hypertension is greater for deep $\mathrm{ICH}$ than for lobar $\mathrm{ICH}_{1}^{38,39}$ hypertension is twice as common in patients with deep $\mathrm{ICH}$ as in those with lobar $\mathrm{ICH}^{40}$ Current smoking $^{35}$ and heavy alcohol consumption ${ }^{41}$ are associated with increased risk of ICH. An Australian case-control study showed an inverse relationship between cholesterol level and the risk of $\mathrm{ICH}^{42}$ Another study found that low total cholesterol and Lowdensity lipoprotein cholesterol levels were associated with more severe $\mathrm{ICH}{ }^{43}$ The use of warfarin increases the risk of $\mathrm{ICH}$ by two- to five-fold, depending upon the intensity of anticoagulation. ${ }^{44}$ Anticoagulation-related ICH is nowadays increasing because of the increased use of oral anticoagulation in elderly population. ${ }^{45}$ Antiplatelet therapy can increase the risk of $\mathrm{ICH}$.

Table 1. Risk factors of intracerebral hemorrhage

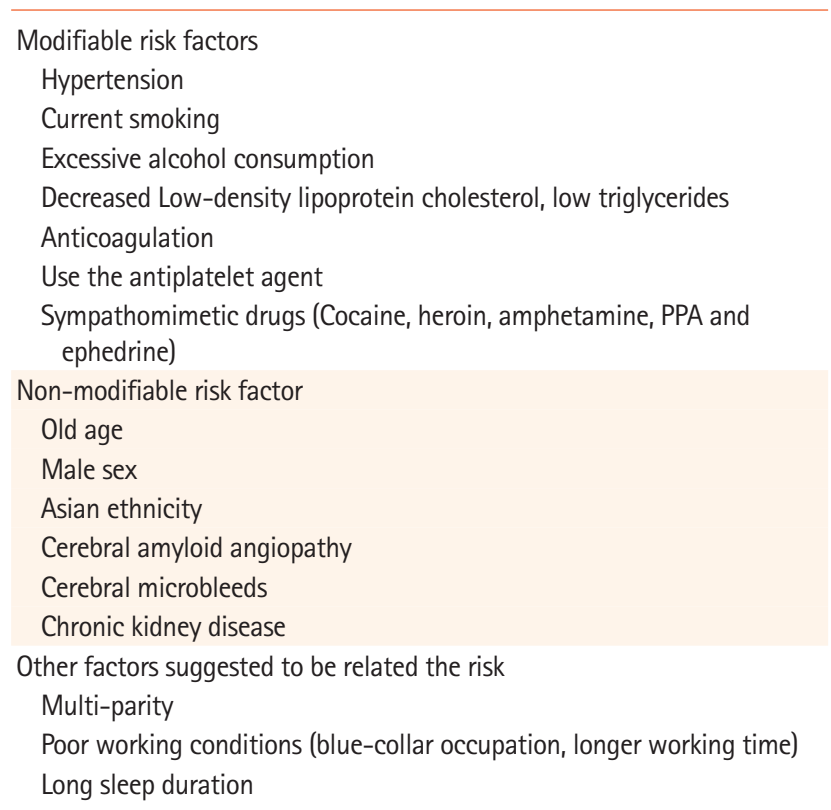

PPA, Phenylpropanolamine.
Several case-control studies did not show an increased ICH risk with antiplatelet use, , $^{42,46}$ but meta-analyses showed that antiplatelet therapy was associated with a small but significant increase in the ICH risk. ${ }^{47,48}$ In addition, a meta-analysis showed that prior antiplatelet use was associated with an increased risk of death after the $\mathrm{ICH}_{1}{ }^{49}$ and another studies demonstrated an increased risk of early hematoma growth with prior antiplatelet use. ${ }^{50,51}$ In particular, dual antiplatelet therapy compared to antiplatelet monotherapy is likely to further increase the ICH risk. In patients with atrial fibrillation, the risk of $\mathrm{ICH}$ is almost twice as high with aspirin plus clopidogrel compared to aspirin alone (0.4 vs. 0.2 percent). ${ }^{52}$

Associations have been reported between $\mathrm{ICH}$ and sympathomimetic drugs such as cocaine, heroin, amphetamine, and ephedrine, particularly in young patients. Phenylpropaolamine in a relatively high dose was an independent risk factor for hemorrhagic stroke, particularly in women. ${ }^{53}$ In a Korean case-control study, low dose of Phenylpropaolamine in cold remedies was also associated with an increased risk of hemorrhagic stroke in women. ${ }^{54}$ Chronic kidney disease was found to increase the risk for ICH in a population-based study, and the association remained significant even after adjusting for covariates. ${ }^{55}$ Chronic kidney disease may be a marker of cerebrovascular small vessel disease, which is the major mechanism of hypertensive ICH. ${ }^{56}$ Platelet dysfunction in patients with chronic kidney disease might also account for the increased risk of $\mathrm{ICH}$.

\section{Cerebral microbleeds (CMBs)}

CMBs are detected in 5 to 23 percent of elderly individuals. ${ }^{57}$ The Framingham study showed that CMBs were more prevalent in individuals with advanced age and males..$^{58}$ In another studies, CMBs were associated with hypertension, diabetes mellitus, and cigarette smoking. ${ }^{57,59} \mathrm{CMBs}$ are associated with an increased risk of spontaneous $\mathrm{ICH}_{1}^{60}$ and may increase the risk of warfarinor antiplatelet-associated ICH. ${ }^{61}$ Therefore, both the benefit and risk should be considered for antithrombotic use in patients with $\mathrm{CMBs}^{62}$

\section{Other potential risk factors}

Increased number of childbirths may be associated with an increased risk of ICH. Compared to women with nulliparity or uniparity, women with multiparity have a significantly higher risk for $\mathrm{ICH}$ with a trend of increasing risk with increasing parity. ${ }^{63}$ Blue-collar occupation, longer working hours, and extended duration of strenuous work activity may be related to an increased risk of $\mathrm{ICH}^{64}$ It was also reported that long sleep duration greater than 8 hours was associated with an increased ICH risk. ${ }^{65}$ 
Table 2. Poor prognostic factors of intracerebral hemorrhage

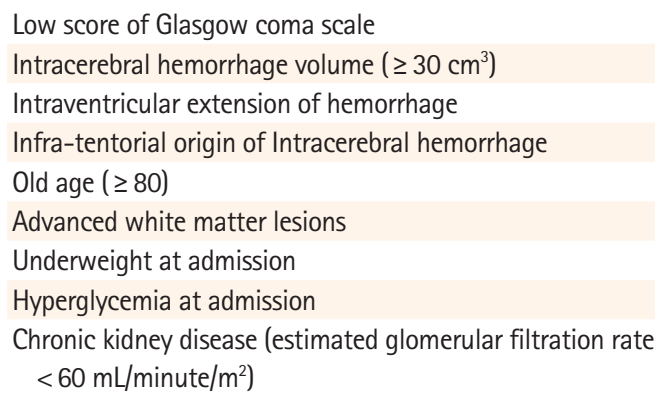

\section{Prognostic factors}

Known poor prognostic factors of ICH include large hematoma volume, hematoma expansion, intraventricular hemorrhage, infra-tentorial location, old age, contrast extravasation on CT scan (spot sign) and the use of anticoagulation (Table 2). ICH Score, a simple clinical grading scale, may help stratify the risk; patients with high ICH score have a high mortality rate. ${ }^{6}$ In Asian studies, fever, low initial Glasgow Coma Scale, large hematoma, intraventricular hemorrhage, and diabetes were independent predictors for poor outcome. ${ }^{66,67}$ Acute brain bleeding analysis, a large case-control study, showed that extensive white matter lesion was associated with lower Glasgow Coma Scale score and higher mortality. ${ }^{68}$ High glucose level at admission or at 24 hours was also associated with an increased risk of bed-ridden status or 30-day mortality, ${ }_{1}^{69}$ Chronic kidney disease (glomerular filtration rate $<60 \mathrm{~mL} /$ minute $/ \mathrm{m}^{2}$ ) was also reported to be associated with poor outcome. ${ }^{70}$ In addition to well known biological factors, early withdrawal of care might impact on the ICH outcome. In a US study, even after adjusting for predictors of ICH mortality, early do-not-resuscitate decision was independently associated with higher short- and long-term mortalities, suggesting that the decision of early withdrawal of care for ICH patients should be cautiously made. ${ }^{71}$ The current US guidelines recommend the postponement of do-not-resuscitate orders until at least the second full day of hospitalization. ${ }^{72}$

\section{Clinical manifestation}

Although some individuals develop ICH during exertion or sudden emotional stress, most ICHs occur during routine activity. The neurologic symptoms usually aggravate over minutes or a few hours. The most common site of ICH is the putamen, and clinical presentations vary by the size and location of $\mathrm{ICH}^{73}$ Common ICH symptoms are headache, nausea, and vomiting. Headache is more common in patients with large hematomas, and is attributed to traction on meningeal pain fibers, increased intracranial pressure, or blood in the cerebrospinal fluid. Small, deep hematomas are rarely associated with headache. Vomiting is reported in about 50\% of patients with hemispheric ICH, and more common in patients with cerebellar hemorrhages. It is usually associated with increased intracranial pressure. Patients with large ICH often have a decreased level of consciousness due to increased intracranial pressure and compression of the thalamus and brainstem. Stupor or coma indicates large ICHs that involve the brainstem reticular activating system. ${ }^{74}$ Seizures reported in about $10 \%$ of patients with $\mathrm{ICH}$ and about $50 \%$ of patients with lobar hemorrhage. Seizures typically occur at the onset of bleeding or within the first 24 hours. ${ }^{75}$ Neurological deterioration is common before and during hospital admission and may indicate early hematoma enlargement or worsening of edema.' Patients with a supratentorial ICH involving the basal ganglia or thalamus have contralateral sensorimotor deficits. Lobar hemorrhages may present with symptoms of a higher cortical dysfunction such as aphasia, neglect, gaze deviation, and hemianopia. In patients with an infratentorial ICH, signs of brainstem dysfunction occur such as ocular motor or other cranial nerve abnormalities, and contralateral motor deficits. ${ }^{2}$ More than $40 \%$ of patients with CAA-associated ICH have some degree of cognitive dysfunction, and the cognitive changes may precede the $\mathrm{ICH}$ in some cases. ${ }^{76,77}$

The prognosis of anticoagulation-associated $\mathrm{ICH}$ is usually grave, and up to $76 \%$ of patients either die or become dependent. $^{78}$ In approximately half of the patients, ICH symptoms progress slowly over 24 hours. ${ }^{79,80}$ The unique fluid-blood interface appearance as a result of uncongealed blood can be seen within 12 hours. ${ }^{81}$ Recently, non-vitamin K antagonist oral anticoagulant (NOAC)-related ICHs are increasingly detected due to the increasing use of NOAC. In a small observational study, patients with NOAC-associated ICH compared to those with warfarin-associated ICH had smaller ICH volumes and better clinical outcomes. ${ }^{82}$ As specific antidotes to NOACs (andexanet alfa for factor Xa inhibitors ${ }^{83,84}$ and idarucizumab for dabigatran ${ }^{85}$ ) have been developed, their effects on the outcome of NOAC-related $\mathrm{ICH}$ need to be investigated.

\section{References}

1. Qureshi Al, Mendelow AD, Hanley DF. Intracerebral haemorrhage. Lancet 2009;373:1632-1644.

2. Qureshi Al, Tuhrim S, Broderick JP, Batjer HH, Hondo H, Hanley DF. Spontaneous intracerebral hemorrhage. N Engl J Med 2001; 344:1450-1460.

3. Garcia JH, Ho KL. Pathology of hypertensive arteriopathy. Neurosurg Clin N Am 1992;3:497-507. 
4. Hong KS, Bang OY, Kang DW, Yu KH, Bae HJ, Lee JS, et al. Stroke statistics in Korea: part I. Epidemiology and risk factors: a report from the korean stroke society and clinical research center for stroke. J Stroke 2013;15:2-20.

5. Krishnamurthi RV, Moran AE, Forouzanfar MH, Bennett DA, Mensah GA, Lawes CM, et al. The global burden of hemorrhagic stroke: a summary of findings from the GBD 2010 study. Glob Heart 2014;9:101-106.

6. Hemphill JC 3rd, Bonovich DC, Besmertis L, Manley GT, Johnston SC. The ICH score: a simple, reliable grading scale for intracerebral hemorrhage. Stroke 2001;32:891-897.

7. Keep RF, Hua Y, Xi G. Intracerebral haemorrhage: mechanisms of injury and therapeutic targets. Lancet Neurol 2012;11:720731.

8. Feigin VL, Lawes CM, Bennett DA, Barker-Collo SL, Parag V. Worldwide stroke incidence and early case fatality reported in 56 population-based studies: a systematic review. Lancet Neurol 2009;8:355-369.

9. Sacco S, Marini C, Toni D, Olivieri L, Carolei A. Incidence and 10 -year survival of intracerebral hemorrhage in a populationbased registry. Stroke 2009;40:394-399.

10. Kannel WB, Wolf PA, Verter J, McNamara PM. Epidemiologic assessment of the role of blood pressure in stroke. The Framingham study. JAMA 1970;214:301-310.

11. Broderick J, Connolly S, Feldmann E, Hanley D, Kase C, Krieger $D$, et al. Guidelines for the management of spontaneous intracerebral hemorrhage in adults: 2007 update: a guideline from the American Heart Association/American Stroke Association Stroke Council, High Blood Pressure Research Council, and the Quality of Care and Outcomes in Research Interdisciplinary Working Group. Stroke 2007;38:2001-2023.

12. Toyoda K. Epidemiology and registry studies of stroke in Japan. J Stroke 2013;15:21-26.

13. van Asch CJ, Luitse MJ, Rinkel GJ, van der Tweel I, Algra A, Klijn CJ. Incidence, case fatality, and functional outcome of intracerebral haemorrhage over time, according to age, sex, and ethnic origin: a systematic review and meta-analysis. Lancet Neurol 2010;9:167-176.

14. Flaherty ML, Woo D, Haverbusch M, Sekar P, Khoury J, Sauerbeck $L$, et al. Racial variations in location and risk of intracerebral hemorrhage. Stroke 2005;36:934-937.

15. Broderick J, Brott T, Tomsick T, Miller R, Huster G. Intracerebral hemorrhage more than twice as common as subarachnoid hemorrhage. J Neurosurg 1993;78:188-191.

16. Jolink WM, Klijn CJ, Brouwers PJ, Kappelle $\sqcup$, Vaartjes I. Time trends in incidence, case fatality, and mortality of intracerebral hemorrhage. Neurology 2015;85:1318-1324.

17. Stein M, Misselwitz B, Hamann GF, Scharbrodt W, Schummer
DI, Oertel MF. Intracerebral hemorrhage in the very old: future demographic trends of an aging population. Stroke 2012;43: 1126-1128.

18. Lovelock CE, Molyneux AJ, Rothwell PM; Oxford Vascular Study. Change in incidence and aetiology of intracerebral haemorrhage in Oxfordshire, UK, between 1981 and 2006: a population-based study. Lancet Neuro/ 2007;6:487-493.

19. González-Pérez A, Gaist D, Wallander MA, McFeat G, GarcíaRodríguez LA. Mortality after hemorrhagic stroke: data from general practice (The Health Improvement Network). Neurology 2013;81:559-565.

20. Liotta EM, Prabhakaran S. Warfarin-associated intracerebral hemorrhage is increasing in prevalence in the United States. $J$ Stroke Cerebrovasc Dis 2013;22:1151-1155.

21. Chan S, Hemphill JC 3rd. Critical care management of intracerebral hemorrhage. Crit Care Clin 2014;30:699-717.

22. Fisher CM. Lacunar strokes and infarcts: a review. Neurology 1982;32:871-876.

23. Charidimou A, Gang Q, Werring DJ. Sporadic cerebral amyloid angiopathy revisited: recent insights into pathophysiology and clinical spectrum. J Neurol Neurosurg Psychiatry 2012;83:124137.

24. Rosand J, Hylek EM, O'Donnell HC, Greenberg SM. Warfarinassociated hemorrhage and cerebral amyloid angiopathy: a genetic and pathologic study. Neurology 2000;55:947-951.

25. Rost NS, Greenberg SM, Rosand J. The genetic architecture of intracerebral hemorrhage. Stroke 2008;39:2166-2173.

26. Phillips MC. Apolipoprotein E isoforms and lipoprotein metabolism. IUBMB Life 2014;66:616-623.

27. Qureshi Al, Suri MF, Ostrow PT, Kim SH, Ali Z, Shatla AA, et al. Apoptosis as a form of cell death in intracerebral hemorrhage. Neurosurgery 2003;52:1041-1047; discussion 1047-1048.

28. Qureshi Al, Ali Z, Suri MF, Shuaib A, Baker G, Todd K, et al. Extracellular glutamate and other amino acids in experimental intracerebral hemorrhage: an in vivo microdialysis study. Crit Care Med 2003;31:1482-1489.

29. Lusardi TA, Wolf JA, Putt ME, Smith DH, Meaney DF. Effect of acute calcium influx after mechanical stretch injury in vitro on the viability of hippocampal neurons. J Neurotrauma 2004;21: $61-72$.

30. Graham DI, McIntosh TK, Maxwell WL, Nicoll JA. Recent advances in neurotrauma. J Neuropathol Exp Neurol 2000;59:641651.

31. Nakamura T, Xi G, Park JW, Hua Y, Hoff JT, Keep RF. Holotransferrin and thrombin can interact to cause brain damage. Stroke 2005;36:348-352.

32. Xi G, Keep RF, Hoff JT. Mechanisms of brain injury after intracerebral haemorrhage. Lancet Neurol 2006;5:53-63. 
33. Wagner KR, Packard BA, Hall CL, Smulian AG, Linke MJ, De Courten-Myers GM, et al. Protein oxidation and heme oxygenase-1 induction in porcine white matter following intracerebral infusions of whole blood or plasma. Dev Neurosci 2002;24:154160.

34. Xi G, Reiser G, Keep RF. The role of thrombin and thrombin receptors in ischemic, hemorrhagic and traumatic brain injury: deleterious or protective? J Neurochem 2003;84:3-9.

35. Ariesen MJ, Claus SP, Rinkel GJ, Algra A. Risk factors for intracerebral hemorrhage in the general population: a systematic review. Stroke 2003;34:2060-2065.

36. Sturgeon JD, Folsom AR, Longstreth WT Jr, Shahar E, Rosamond WD, Cushman M. Risk factors for intracerebral hemorrhage in a pooled prospective study. Stroke 2007;38:27182725.

37. O'Donnell MJ, Xavier D, Liu L, Zhang H, Chin SL, Rao-Melacini $P$, et al. Risk factors for ischaemic and intracerebral haemorrhagic stroke in 22 countries (the INTERSTROKE study): a casecontrol study. Lancet 2010;376:112-123.

38. Zia $E_{1}$ Hedblad B, Pessah-Rasmussen $H$, Berglund $G$, Janzon $L$, Engström $\mathrm{G}$. Blood pressure in relation to the incidence of cerebral infarction and intracerebral hemorrhage. Hypertensive hemorrhage: debated nomenclature is still relevant. Stroke 2007; 38:2681-2685.

39. Martini SR, Flaherty ML, Brown WM, Haverbusch M, Comeau $M E$, Sauerbeck $L R$, et al. Risk factors for intracerebral hemorrhage differ according to hemorrhage location. Neurology2012; 79:2275-2282.

40. Jackson CA, Sudlow CL. Is hypertension a more frequent risk factor for deep than for lobar supratentorial intracerebral haemorrhage? J Neurol Neurosurg Psychiatry 2006;77:12441252.

41. Grønbaek H, Johnsen SP, Jepsen P, Gislum M, Vilstrup H, TageJensen $U$, et al. Liver cirrhosis, other liver diseases, and risk of hospitalisation for intracerebral haemorrhage: a Danish population-based case-control study. BMC Gastroenterol 2008; 8:16.

42. Thrift AG, McNeil JJ, Forbes A, Donnan GA. Risk factors for cerebral hemorrhage in the era of well-controlled hypertension. Melbourne Risk Factor Study (MERFS) Group. Stroke 1996;27: 2020-2025.

43. Mustanoja S, Strbian D, Putaala J, Meretoja A, Curtze S, Haapaniemi $E_{1}$ et al. Association of prestroke statin use and lipid levels with outcome of intracerebral hemorrhage. Stroke 2013; 44:2330-2332.

44. Flaherty ML, Tao $H$, Haverbusch M, Sekar P, Kleindorfer D, Kissela $B$, et al. Warfarin use leads to larger intracerebral hematomas. Neurology 2008;71:1084-1089.
45. Flaherty ML, Kissela B, Woo D, Kleindorfer D, Alwell K, Sekar P, et al. The increasing incidence of anticoagulant-associated intracerebral hemorrhage. Neurology 2007;68:116-121.

46. García-Rodríguez LA, Gaist D, Morton J, Cookson C, GonzálezPérez A. Antithrombotic drugs and risk of hemorrhagic stroke in the general population. Neurology 2013;81:566-574.

47. He J, Whelton PK, Vu B, Klag MJ. Aspirin and risk of hemorrhagic stroke: a meta-analysis of randomized controlled trials. JAMA 1998;280:1930-1935.

48. Hart RG, Halperin JL, McBride R, Benavente 0, Man-Son-Hing $M$, Kronmal RA. Aspirin for the primary prevention of stroke and other major vascular events: meta-analysis and hypotheses. Arch Neurol 2000;57:326-332.

49. Thompson BB, Béjot $Y$, Caso V, Castillo J, Christensen $\mathrm{H}$, Flaherty $\mathrm{ML}$, et al. Prior antiplatelet therapy and outcome following intracerebral hemorrhage: a systematic review. Neurology 2010;75:1333-1342.

50. Naidech AM, Jovanovic B, Liebling S, Garg RK, Bassin SL, Bendok $B R$, et al. Reduced platelet activity is associated with early clot growth and worse 3-month outcome after intracerebral hemorrhage. Stroke 2009;40:2398-2401.

51. Davis SM, Broderick J, Hennerici M, Brun NC, Diringer MN, Mayer SA, et al. Hematoma growth is a determinant of mortality and poor outcome after intracerebral hemorrhage. Neurology 2006;66:1175-1181.

52. ACTIVE Investigators, Connolly SJ, Pogue J, Hart RG, Hohnloser $\mathrm{SH}$, Pfeffer $\mathrm{M}$, et al. Effect of clopidogrel added to aspirin in patients with atrial fibrillation. N Engl J Med 2009;360:20662078.

53. Kernan WN, Viscoli CM, Brass LM, Broderick JP, Brott T, Feld-

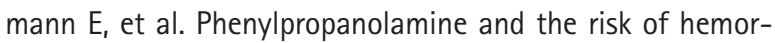
rhagic stroke. N Engl J Med 2000;343:1826-1832.

54. Yoon BW, Bae HJ, Hong KS, Lee SM, Park BJ, Yu KH, et al. Phenylpropanolamine contained in cold remedies and risk of hemorrhagic stroke. Neurology 2007;68:146-149.

55. Bos MJ, Koudstaal PJ, Hofman A, Breteler MM. Decreased glomerular filtration rate is a risk factor for hemorrhagic but not for ischemic stroke: the Rotterdam Study. Stroke 2007;38: 3127-3132.

56. Ovbiagele B, Wing JJ, Menon RS, Burgess RE, Gibbons MC, Sobotka I, et al. Association of chronic kidney disease with cerebral microbleeds in patients with primary intracerebral hemorrhage. Stroke 2013;44:2409-2413.

57. Goos JD, Henneman WJ, Sluimer JD, Vrenken H, Sluimer IC, Barkhof $F$, et al. Incidence of cerebral microbleeds: a longitudinal study in a memory clinic population. Neurology 2010;74: 1954-1960.

58. Jeerakathil T, Wolf PA, Beiser A, Hald JK, Au R, Kase CS, et al. 
Cerebral microbleeds: prevalence and associations with cardiovascular risk factors in the Framingham Study. Stroke 2004; 35:1831-1835.

59. Cordonnier C, Al-Shahi Salman R, Wardlaw J. Spontaneous brain microbleeds: systematic review, subgroup analyses and standards for study design and reporting. Brain 2007;130: 1988-2003.

60. Charidimou A, Kakar P, Fox Z, Werring DJ. Cerebral microbleeds and recurrent stroke risk: systematic review and meta-analysis of prospective ischemic stroke and transient ischemic attack cohorts. Stroke 2013;44:995-1001.

61. Lovelock CE, Cordonnier C, Naka H, Al-Shahi Salman R, Sudlow CL; Edinburgh Stroke Study Group, et al. Antithrombotic drug use, cerebral microbleeds, and intracerebral hemorrhage: a systematic review of published and unpublished studies. Stroke 2010;41:1222-1228.

62. Lee SH, Ryu WS, Roh JK. Cerebral microbleeds are a risk factor for warfarin-related intracerebral hemorrhage. Neurology2009; 72:171-176.

63. Jung SY, Bae HJ, Park BJ, Yoon BW; Acute Brain Bleeding Analysis Study Group. Parity and risk of hemorrhagic strokes. Neurology 2010;74:1424-1429.

64. Kim BJ, Lee SH, Ryu WS, Kim CK, Chung JW, Kim D, et al. Excessive work and risk of haemorrhagic stroke: a nationwide case-control study. Int J Stroke 2013;8 Suppl A100:56-61.

65. Kim TJ, Kim CK, Kim Y, Jung S, Jeong HG, An SJ, et al. Prolonged sleep increases the risk of intracerebral haemorrhage: a nationwide case-control study. Eur J Neurol 2016;23:10361043.

66. Poungvarin N, Suwanwela NC, Venketasubramanian N, Wong LK, Navarro JC, Bitanga E, et al. Grave prognosis on spontaneous intracerebral haemorrhage: GP on STAGE score. J Med Assoc Thai 2006;89 Suppl 5:S84-S93.

67. Chen HS, Hsieh CF, Chau T, Yang CD, Chen YW. Risk factors of in-hospital mortality of intracerebral hemorrhage and comparison of ICH scores in a Taiwanese population. Eur Neurol $2011 ; 66: 59-63$

68. Lee SH, Kim BJ, Ryu WS, Kim CK, Kim N, Park BJ, et al. White matter lesions and poor outcome after intracerebral hemorrhage: a nationwide cohort study. Neurology 2010;74:15021510.

69. Lee SH, Kim BJ, Bae HJ, Lee JS, Lee J, Park BJ, et al. Effects of glucose level on early and long-term mortality after intracerebral haemorrhage: the Acute Brain Bleeding Analysis Study. Diabetologia 2010;53:429-434.

70. Miyagi T, Koga M, Yamagami H, Okuda S, Okada Y, Kimura K, et al. Reduced estimated glomerular filtration rate affects outcomes 3 months after intracerebral hemorrhage: the stroke acute management with urgent risk-factor assessment and improvement-intracerebral hemorrhage study. J Stroke Cerebrovasc Dis 2015;24:176-182.

71. Zahuranec DB, Brown DL, Lisabeth LD, Gonzales NR, Longwell PJ, Smith MA, et al. Early care limitations independently predict mortality after intracerebral hemorrhage. Neurology2007; 68:1651-1657.

72. Hemphill JC 3rd, Greenberg SM, Anderson CS, Becker K, Bendok BR, Cushman $M$, et al. Guidelines for the management of spontaneous intracerebral hemorrhage: a guideline for healthcare professionals from the American Heart Association/ American Stroke Association. Stroke 2015;46:2032-2060.

73. Manno EM, Atkinson JL, Fulgham JR, Wijdicks EF. Emerging medical and surgical management strategies in the evaluation and treatment of intracerebral hemorrhage. Mayo Clin Proc 2005;80:420-433.

74. Steiner $T$, Kaste $M$, Forsting $M$, Mendelow $D$, Kwiecinski $H$, Szikora I, et al. Recommendations for the management of intracranial haemorrhage - part I: spontaneous intracerebral haemorrhage. The European Stroke Initiative Writing Committee and the Writing Committee for the EUSI Executive Committee. Cerebrovasc Dis 2006;22:294-316.

75. Vespa PM, O'Phelan K, Shah M, Mirabelli J, Starkman S, Kidwell $C$, et al. Acute seizures after intracerebral hemorrhage: a factor in progressive midline shift and outcome. Neurology 2003;60:1441-1446.

76. Vinters HV. Cerebral amyloid angiopathy. A critical review. Stroke 1987;18:311-324.

77. Yoshimura M, Yamanouchi $H$, Kuzuhara $S$, Mori $H$, Sugiura $S$, Mizutani T, et al. Dementia in cerebral amyloid angiopathy: a clinicopathological study. J Neurol 1992;239:441-450.

78. Fang MC, Go AS, Chang Y, Hylek EM, Henault LE, Jensvold NG, et al. Death and disability from warfarin-associated intracranial and extracranial hemorrhages. Am J Med 2007;120:700705.

79. Kase CS, Robinson RK, Stein RW, DeWitt LD, Hier DB, Harp DL, et al. Anticoagulant-related intracerebral hemorrhage. Neurology 1985;35:943-948.

80. Fredriksson K, Norrving B, Strömblad LG. Emergency reversal of anticoagulation after intracerebral hemorrhage. Stroke 1992; 23:972-977.

81. Livoni JP, McGahan JP. Intracranial fluid-blood levels in the anticoagulated patient. Neuroradiology 1983;25:335-337.

82. Wilson D, Charidimou A, Shakeshaft C, Ambler G, White M, Cohen $\mathrm{H}_{\text {, et }}$ al. Volume and functional outcome of intracerebral hemorrhage according to oral anticoagulant type. Neurology 2016;86:360-366.

83. Connolly SJ, Milling TJ Jr, Eikelboom JW, Gibson CM, Curnutte 
JT, Gold A, et al. Andexanet alfa for acute major bleeding associated with factor Xa inhibitors. N Engl J Med 2016;375:11311141.

84. Siegal DM, Curnutte JT, Connolly SJ, Lu G, Conley PB, Wiens $B L$, et al. Andexanet alfa for the reversal of factor $X a$ inhibitor activity. N Engl J Med 2015;373:2413-2424.

85. Pollack CV Jr, Reilly PA, Eikelboom J, Glund S, Verhamme P, Bernstein RA, et al. Idarucizumab for dabigatran reversal. $N$ Engl J Med 2015;373:511-520. 